\title{
Nephropathy due to Ciclosporin
}

National Cancer Institute

\section{Source}

National Cancer Institute. Nephropathy due to Ciclosporin. NCI Thesaurus. Code

C123135.

Kidney damage resulting from ciclosporin. 